Túlio Batista Franco ${ }^{1}$ Emerson Elias M erhy ${ }^{2}$
${ }^{1}$ Departamento de Planejamento em Saúde, Instituto deSaúdeda Comunidade, UFF. Av. M arquês de Paraná, 303/ 3o andar/anexo, Centro. 24030-210 Niterói RJ. tuliofranco@uol.com.br

${ }^{2}$ Departamento de Clínica M édica, Universidade Federal do Rio deJaneiro.

\section{Atenção domiciliar na saúde suplementar: dispositivo da reestruturação produtiva}

\author{
H ome health care in supplementary care: \\ a device for a productive restructuring
}

Abstract This study discusses the role the Brazilian $\mathrm{H}$ ome $\mathrm{H}$ ealth Care Program (Programa de Atenção Domiciliar - PAD) plays in supplementary care using the example of a Group Care provider headquartered in Rio de Janeiro. The purpose of the study was to understand how home health care is produced by verifying the interaction between the medical team, beneficiaries and family members considering that the service in this care model is delivered in the micro-political scenery of the process, in the client's own home. The assessment of this program must consider: infrastructure and logistics, beneficiary eligibility criteria, the care-network formed in support of the PAD and above all the work process. Especially thelatter is a strong indicator, in the present case characterized by an eminently multi-professional team operating in networks with integrated therapeutic projects. For the professionals, $\mathrm{H}$ ome $\mathrm{H}$ ealth $\mathrm{Care}$ has the meaning of an innovative and highly valuable approach to care delivery. The article concludes considering the PAD an important device for a fruitful restructuring of supplementary care through different ways of care delivery.

Key words Supplementary care, Home health care, Productive restructuring, Work process
Resumo Esteestudo discute o Programa deAtenção Domiciliar (PAD) na saúde suplementar, utilizando o caso de uma operadora de medicina de grupo, sediada no Rio de Janeiro. A pesquisa procura perceber o modo como se produz a atenção domiciliar ebuscou verificá-lo nas relações de cuidado entre equipe, o beneficiário e familiares, entendendo que o modelo assistencial se realiza no cenário da micropolítica do processo de trabalho, no domi ćlilo enquanto espaço de produção do cuidado. $\mathrm{Na}$ análise do Programa, aparecem como aspectos importantes a infra- estrutura e logística utilizadas; os critérios de elegibilidade do beneficiário; a rede de cui dados que se forma em apoio ao PAD; e sobretudo o processo de trabalho. Este por sua vez tem uma alta potência para revelar a assistência e, no caso estudado, se caracteriza por um trabalho fortemente multiprofissional, que opera em redes, com projetos terapêuticos integrais etraz uma importante "implicação" dos profissionais com o significado da atenção domiciliar, enquanto algo inovador e de alto valor para o cuidado. 0 artigo conclui que o PAD se afirma como um importante dispositivo de reestruturação produtiva na saúde suplementar, configurando assim modos diferentes de produzir o cuidado.

Palavras-chave Saúde suplementar, Atenção domiciliar, Reestruturação produtiva, Processo de trabalho 
Introdução

A atenção domiciliar na saúde suplementar se insere no contexto em que as operadoras introduzem novas tecnologias de cuidado à saúde, para fazer frente aos seus altos custos operacionais, decorrentes do modelo tecnoassistencial predominante na produção de procedimentos, conforme nos informa Malta et al. ${ }^{1}$ e ANS ${ }^{2}$. A própria Agência N acional de SaúdeSuplementar (ANS) tem buscado pautar a questão da assistência, quando formulou o Programa de Qualificação da Saúde Suplementar ${ }^{3}$ que setornou uma política da Agência, dado a sua relevância.

No sentido geral do termo, a atenção domiciliar é a forma mais ampla de cuidados domiciliários, abrangendo todo tipo de ação neste campo. As outras classificações discutidas por Lacerda et al. ${ }^{4}$ são 0 atendimento domiciliar, que define ações de "caráter ambulatorial" segundo a ANVISA ${ }^{5}$; internação domiciliar, definida como os cuidados mais intensivos e a visita domiciliar.

Vários autores atribuem o crescimento dos Programas de Atenção Domiciliar à "mudança do perfil etário da população" 6,7 , cujo aumento da população idosa impacta em necessidades e custos em relação aos serviços de saúde. Este é portanto mais um dado que corrobora com a idéi a geral de que as operadoras se vêem compelidas a iniciarem um processo de reestruturação produtiva, que tem suas bases na busca por um novo modelo de produção do cuidado no sentido de reduzir seus custos operacionais.

A "reestruturação produtiva", descrita inicialmente como um processo de mudança desencadeado pela incorporação tecnológica na saúde, conforme Denise Pires ${ }^{8}$, foi demonstrando ser um fenômeno que ocorre também sob impacto de mudanças no processo de trabalho, sobretudo na sua dimensão relacional. Por outro lado, ela não significa obrigatoriamente uma inversão das usuais tecnologias utilizadas no processo produtivo da saúde, ou seja, ela opera mudanças, mas não necessariamente produz uma ruptura com o modelo médico-hegemônico, como alerta Emerson Merhy ${ }^{9}$, pois o processo de trabalho pode ainda continuar centrado na lógica instrumental ${ }^{10,11}$.

0 núcleo de maior tensão para a reestruturação produtiva está no trabalho vivo em ato, pois édele quevem a potência instituintedo processo de trabalho, e por outro lado é aí também que ocorrem os processos de captura pelo modelo hegemônico. Sua micropolítica revela a ação dos sujeitos construindo redes enquanto produzem o cuidado, operam linhas de cuidado integral, conforme discute Cecílio e M erhy ${ }^{12}$. Elas se formam nas relações entre os trabalhadores, deles com os usuários e em linhas de conexão para fora de cada unidade organizacional, seja esta um estabelecimento de saúde ou o próprio domicílio. Estas relações se produzem em fluxos abertos que operam objetivamente na realidade e também a partir de certos campos simbólicos, configurando redes rizomáticas, isto é, que se estabelecem continuamente, com muitas entradas, tal como descrito por Deleuze e Guattari ${ }^{13}$.

A integralidade do cuidado [da qual trata 0 tema das linhas do cuidado] de que cada pessoa real necessita freqüentemente transversaliza todo o 'si stema'. Não há integralidaderadical sem a possibilidade de transversalidade. A integralidade do cuidado só podeser obtida em rede ${ }^{12}$. O pinião corroborada também por Franco que afirma serem as redes imanentes ao trabalho em saúde ${ }^{14}$. As linhas de cuidado são a expressão material epragmática do conceito de integralidade, pois ela só é pensada enquanto uma prática de cuidado, operando de forma sistêmica e incorporada no processo de trabalho.

A subjetividade énecessariamente uma categoria de análise importante, que se coloca no âmbito do processo de trabalho. Seu núcleo, o desejo, atua como força propulsora da ação dos sujeitos no mundo, ese refere ao modo como as pessoas produzem o meio social ao qual estão inseridas, o socius, segundo Deleuze e Guattari ${ }^{15}$, também descrito por Baremblitt ${ }^{16}$. A atenção domiciliar produz uma intrincada redeintersubjetiva, encontros que resultam em subjetivações, isto é, produção de novas subjetividades, que se traduz em uma nova interação com o microcosmo do processo de trabalho.

0 caráter de substitutividade ${ }^{17}$ de um dado modelo produtivo, e isso é particularmente importante no caso da atenção domiciliar, pode ser verificado pelo processo de reestruturação produtiva. Este artigo é devedor da pesquisa sobre atenção domiciliar na saúde suplementar, real izada pela Universidade Federal Fluminense (UFF), em cooperação técnica-científica com a UniversidadeFederal do Rio de Janeiro (UFRJ), com apoio daAgência Nacional deSaúde Suplementar (ANS) e Organização Pan-Americana de Saúde (OPAS).

\section{M etodologia}

Trata-se de um estudo qualitativo que utilizou como instrumentos de coleta de dados a pesquisa bibliográfica, referenciados no campo da "pro- 
dução do cuidado", com foco na micropolítica dos processos de trabalho em saúde. A pesquisa documental buscou referências junto aos sítios das operadoras e da ANS na Internet. Foram realizadas entrevistas com informantes estratégicos, com roteiro semi-estruturado, sendo entrevistadoso diretor técnico da operadora, sob cuja direção está a coordenação do Programa de Atenção Domiciliar. Foram entrevistados ainda no âmbito da prestadora de serviços de home care que atende à operadora, a sua gestora, a coordenadora das equipes do Programa de Atenção D omiciliar, os trabalhadores que compõem a equipe e beneficiários ou cuidadores inseridos nos respectivos programas. Além das entrevistas, foi realizada visita ao domicílio, observação direta com roteiro e caderno de campo, onde se verificou o processo de trabalho da equipe e sua relação de trabalho com o beneficiário e sua família. Também foi realizada visita técnica à sede da prestadora de home care, com acesso a todas as unidades de apoio ao Programa deAtenção Domiciliar.

0 objetivo geral da pesquisa é o de revelar e analisar o modelo de Programa de Atenção Domiciliar na saúde suplementar, no segmento medicina de grupo, tendo como foco os processose tecnologias de trabalho em saúde, buscando compreender o modo de produção do cuidado e seus processos de mudança, que caracterizem uma reestruturação produtiva.

Os objetivos específicos são de descrever os aspectos organizacionais e de logística utilizados pela prestadora de home care; descrever e analisar os critérios de elegibilidade dos beneficiários ao PAD; analisar o processo de trabalho com base nas suas dimensões tecnológicas e subjetivas, entendendo-o como o centro de tensões produtivas, incluindo nestecontexto as muitas relações estabelecidas a partir do cuidado domiciliário.

Os dados foram analisados com base na matriz discursiva dos sujeitos da pesquisa, agrupados por marcadores, que dão sentido às duas dimensões que compõem este estudo sobre a atenção domiciliar e que estão diretamente vinculados ao campo especifico da produção do cuidado.

\section{Marcadores analíticos}

- Aspectos organizacionais e de logística: reúnem os recursos materiais para o PAD, inclusive os provenientes do trabalho;

- A gestão do processo de trabalho e educação na saúde: diz respeito à micro-regulação do campo operadora eprestador, no âmbito do PAD;
- Critérios de ingresso no PAD e redes de cuidado integral: trata do acesso ao PAD, a sustentabilidade do Programa e a capacidade em manter o beneficiário sob cuidados especiais mesmo com alta do PAD;

- Micropolítica do processo de trabalho no PAD: éo núcleo da produção do cuidado na atenção domiciliar, efala da ação cotidiana dos sujeitos trabalhadores, na relação entre si e com o beneficiário, cuidador efamília.

\section{Resultados}

A atenção domiciliar na saúde suplementar não é regulamentada pela ANS, ela obedece apenas à regulamentação da ANVISA para esse tipo de serviço, feita através da Resolução da Diretoria Colegiada ( $\left.\operatorname{RDC} n^{\circ} 11 / 2006\right)^{5}$. Ela não consta nos contratos das operadoras com sua clientela, sendo considerada um produto adicional ofertado aos beneficiários e, sendo assim, a definição da modelagem e do funcionamento dos programas fica a cargo da própria operadora, e quando for o caso, isto é feito conjuntamente com a prestadora desse tipo de serviço.

$\mathrm{Na}$ apresentação dos resultados, assinalamos os seguintes marcadores: aspectos organizacionais e de logística; a gestão do trabalho e educação na saúde; critérios de ingresso no PAD eredes de cuidado; micropolítica do processo de trabalho.

\section{Aspectos organizacionais e de logística}

A operadora mantém contrato com uma empresa de home care para operar as ações de cuidado nos domicílios. Tem atualmente em torno de 500 beneficiários nestemodelo deassistência, nos estados de Rio de Janeiro e São Paulo. Trabal ha com o seguinte critério de classificação das suas atividades: a) internação domiciliar: é considerada a atividade domiciliar a beneficiários dependentes do trabal ho de enfermagem 24 horas, com ou sem ventilação mecânica. b) cuidado domiciliar: é considerada a atividade dependente do trabalho de enfermagem por 12 ou 6 horas, e ainda os procedimentos diversificados, ações de acompanhamento, suporte e orientação aos beneficiários.

Para organizar sua atividade de cuidados domiciliários, a prestadora divide o território no qual atua em áreas geograficamente referenciadas. N estas vincula em torno de trinta beneficiários, tendo uma equipe formada por um médico e uma enfermeira. Além desses profissionais que 
estão inseridos na equipe do homecare, a empre sa conta com uma nutricionista, uma assistente social da operadora, além de especialistas, como ortopedistas, cardiologista, urologista e ginecologista, que atuam matricialmente na condução do projeto terapêutico, eavaliação para ingresso do beneficiário, ou alta do Programa, conforme solicitação médica.

Há estruturas de almoxarifado, suprimentos demateriais emedicamentos, transportede equipe ebeneficiários. 0 acesso aos serviços deapoio diagnóstico é garantido mediante a rede conveniada com a operadora e, quando necessário, transporte para esses estabelecimentos. $\mathrm{Na}$ estrutura de apoio, a equipe de trabal hadores e os beneficiários contam com:

- Call center: disponibilizado 24 horas para orientação aos cuidadores quetrabalham no programa, ben eficiários e familiares atendidos;

. Follow up: o beneficiário que tem alta do programa tem um acompanhamento pelo programa que faz contato com o mesmo nos $3 \circ$, 70, 150 , e 30 o dias, com objetivo de avaliar suas condições após a alta;

. Prontuário eletrônico: 0 prontuário eletrônico éum recurso importante para o trabalho no programa, pois possibilita a qualquer membro da equipe acessar as informações pertinentes ao beneficiário, assim como 0 apoio do call center para orientação ao mesmo ou seu familiar;

. O uvidoria: tem a função de receber sugestões e críticas ao programa, repassando as mesmas para a coordenação e/ou outros órgãos internos de acompanhamento.

\section{Gestão do trabalho e educação na saúde}

Os profissionais da prestadora de home care são divididos entre contratados pela própria e terceirizados. Háainda os quetêm vínculo com a operadora e trabalham no PAD, especialmente especial istas que participam das equipes matriciais. Todo profissional que ingressa no programa dehome care recebe um treinamento com o tema das relações com o beneficiário e a família, no ambiente domiciliar, sendo esta considerada uma questão crítica na atenção domiciliar.

Há treinamento continuado que busca motivar os trabalhadores através de premiação dos mesmos. A operadora possui um programa de estímulo ao estudo superior, através do custeio de uma parte da mensalidade da faculdade. São candidatos a esse apoio os técni cos que possuem vínculos com a operadora de no mínimo três anos. Há treinamentos que envolvem também os temas das relações humanas, comportamento e ética.

Critérios de ingresso ao PAD

e rede de cuidado integral

Os critérios de elegibilidade para ingresso no programa de cuidados ou internação domiciliar indicam beneficiários dependentes deinternação hospitalar prolongada; perfil nosológico quetorna possível realizar os cuidados em ambiente domiciliar, por exemplo, tratamento de feridas, antibioticoterapia, suporte pós-internação, acompanhamento para beneficiários portadores de doenças crônicas.

Para ingressar no programa, énecessário que o ben eficiário tenha indicação de algum médico da operadora. A pós essa indicação, ele passa por uma avaliação da equipe do programa para análise das suas condições socioeconômicas, a ambiência do domicílio, o desejo da família em ter a pessoa em casa e a garantia de um cuidador. A prestadora tem uma grande flexibilidade no julgamento da el egibilidade de cada ben eficiário. A equipe de avaliadores é composta por uma enfermeira, uma médica e, quando necessário, fisioterapeuta, em conjunto com a prestadora e a operadora de home care.

Um problema importante enfrentado pelo programa diz respeito à "alta", pois os familiares têm uma grande resistência em assumir os cuidados rotineiros após terem vivenciado o PAD. Há casos de ações judiciais para manutenção do Programa deAtenção Domiciliar, mesmo quenos critérios da equipe e prestadora não haja indicação técnica para isso.

Os profissionais começam a trabal har a "alta" desde 0 ingresso no Programa, procurando transferir conhecimento, tecnologias de cuidado aos familiares e realizando um trabalho de "desmame", como é chamada a alta gradativa, para amenizar o impacto do desligamento do beneficiário do PAD. Nesse sentido, a própria operadora mantém outros programas de suporte à sua clientela, não necessariamentedirigidosà alta, mas podem contribuir para que a família se sinta mais segura em assumir os cuidados ao seu familiar. São eles:

a) O Projeto Gestor, que é o monitoramento pelo telefone, depacientes crônicos, em sua maioria, idosos, e tem como objetivo principal gerenciar o estado de saúde desses pacientes para evitar intercorrências ereinternações;

b) O Total Care, queé um ambulatório especializado. É direcionado para o tratamento de 
pacientes crônicos, em geral, diabéticos, hipertensos, cardiopatas. Tem uma preocupação com a qualidade de vida, realizando atividades degrupos e apoio psicológico;

c) Projeto Onco Care, direcionado para pacientes com câncer, que necessitam terminar 0 ciclo de quimioterapia, ou estão sob cuidados paliativos. É utilizada a mesma estrutura do home care; porém, existem suas especificidades em virtude da complexidade do perfil clínico desses pacientes.

\section{Micropolítica do processo de trabalho}

0 trabalho de coordenação do programa é realizado por uma médica que tem a função de fazer o primeiro contato com a família, para explicar a estrutura do home care e apresentar o serviço; intermediar os problemas entre a equipe, familiares, cuidadores, prestadora e operadora; coordenar o trabalho de logística de enfermagem, fisioterapeutas, médicos; montagem da estrutura de enfermagem no domicílio; verificar a elegibilidade do beneficiário ao PAD; constituir a rede decuidados com a equipe quefaz as visitas domiciliares, dividir os casos entre eles.

A assistente social contribui com a avaliação do beneficiário, nos aspectos socioeconômicos e condições gerais da família, para admissibilidade nos programas de cuidados ou internação domiciliar.

0 profissional de enfermagem tem assumido os cargos de coordenação das áreas geográficas de referência para as equipes. O squeestão na assistência direta possuem funções clínicas próprias dos cuidados exercidos pela enfermagem e realizam os treinamentos dos cuidadores.

Para a operadora, o enfermeiro é visto como figura central no processo de produção do cuidado, seja pela intermediação que faz com os demais profissionais, seja pelo vínculo que constrói com a família e ben eficiário.

0 vínculo, enquanto diretriz do modelo assistencial, é indicador de positividade nas relações de cuidado, pois através do vínculo se consegue um processo de trabalho mais dialógico, interativo, com pactuação do projeto terapêutico e, sobretudo, facilita a relação entre todos os sujeitos envolvidos no processo de cuidado. M as, por outro lado, a operadora manifesta receio de que o vínculo possa posteriormente dificultar a alta do ben eficiário, o que contraria seu objetivo, assim como o vínculo é confundido com sentimentos afetuosos que podem "contaminar" o trabal ho técnico, inconvenientes ao trabalho no
PAD. Há uma tensão permanente entre a lógica instrumental de condução dos projetos terapêuticos e outra mais acolhedora, que se processa na intersubjetividade presente nas relações.

Os profissionais consideram que os treinamentos ofertados pela operadora ficam centradosnos aspectos clínicos e epidemiológicos, contemplando pouco as questões relacionais, que são também demandas importantes do programa. Informam que não há um suporte psicológico para cuidar de questões que são singulares às relações no ambientedomiciliar. A presença da equipecotidianamenteno domicílio podeagravar um cenário já tenso na família e ela se ressente de suporte técnico para trabalhar com este cenário.

o Programa de Atenção Domiciliar, mesmo que fundado para a redução de custos, é ressignificado pelos trabalhadores, que o adotam como algo inovador. Sobretudo, verifica-se que o trabalho no PAD faz com que os próprios profissionais encontrem novos sentidos para eles mesmos, um processo de subjetivação em curso, conforme nos fala Guattari ${ }^{18}$, que coloca estetrabalhador profundamenteenvolvido, "implicado" no sentido dado por Lourau citado por Altoé ${ }^{19}$, quando este envolvimento opera no sentido de organizar a própria atuação deste trabalhador, no mundo da produção do cuidado, do qual ele é o principal protagonista.

Fica clara uma dimensão subjetiva a ser considerada na produção do Programa de Atenção Domiciliar. A implicação do trabalhador com 0 PAD vai se formando a partir de uma imagem idealizada que ele faz do caráter inovador e humanitário da atenção domiciliar. Isso faz com que ele o incorpore como uma nobre "missão" a ser desenvolvida, eéassim que opera seu processo de trabalho, com uma forma de agir que está acima do compromisso e do envolvimento; é como se el estivesse contaminado por um sentimento quase "religioso", de realizar seu trabalho no cuidado domiciliar. 0 efeito que a implicação produz no caso estudado é de al to compromisso com as ações decuidado e, singularmente, deuma prática dialógica na relação entre a equipe, os beneficiários efamiliares.

\section{Revelações do modelo estudado}

O Programa de Atenção D omiciliar é dependente de uma articulada rede de serviços e uma importante estrutura organizacional, como o de equipes de apoio, suportetécnico, grandelogística para provimento de insumos, comunicações e transporte. 
Os critérios de elegibilidade do programa focam em uma clientela de alto consumo e, portanto, custosa para a operadora: doentes crônicos, beneficiários quefazem grande utilização da internação hospitalar, unidades de pronto atendimento e os que se encontram em fase terminal da sua doença. Importa registrar que a operadora trabalha com critério de risco, associando o perfil nosológico ao de consumo e custos operacionais, fazendo uma complexa análise para a admissão do beneficiário. Diferentemente deum hospital, onde as condições de internação estão controladas a priori, no domicílio elas são produzidas pela equipe, sob interferências da própria família, considerando ainda que esta deva assumir parte significativa dos cuidados e, em muitos casos, parte importante dos custos.

A análise socioeconômica para ingresso no programa tornou-se particularmente importante em função da maior presença no mercado dos contratos corporativos e ingresso de um contingente de operários destas empresas no sistema suplementar. Os custos adicionais à família, quando tem um familiar sob cuidados domiciliários, estão associados principalmente a despe sas com medicamentos de uso pela via oral, materiais de consumo, um aumento no gasto com energia elétrica e estrutura de apoio como lavanderia, dieta e, para certos casos, o cuidador pode ser al guém da família (que às vezes precisa parar de trabalhar para fazer o cuidado ao beneficiário), ou contratado.

Os custos para a família têm impacto diferenciado. $\mathrm{N}$ aturalmente, os mais pobres sofrem maior impacto relativo à sua renda do que os de classe média, média-alta. E está na transferência de certos custos para as famílias uma das fontes de redução do custeio dos serviços de saúde pelas operadoras. Com o status jurídico-institucional atual do PAD, pelo qual ele é considerado um "benefício", não contratualizado e não passível de regulação, prevalecem nos programas as regras ditadas pelas operadoras, mesmo que elas se disponham a flexibilizar os critérios de admissibilidade.

Em relação ao modo de produção do cuidado, algumas questões aparecem como estruturantes para o processo de trabalho e vão modelando o seu perfil tecnoassistencial, quais sejam:

a) Trabalho em rede: O PAD, embora tenha sua ação mais diretamente vinculada ao domicílio, édependente de uma bem articulada rede de serviços e profissionais de saúde, que fazem com que ele possa funcionar adequadamente. Essa rede é constitutiva do programa, ela opera em fluxos de conexão permanente entre o médico prescritor, a equipe assistencial e todos os recursos de logística e infra-estrutura mobilizados no processo de trabalho, e também os serviços que são requisitados após a internação domiciliar, como já foram relacionados anteriormente, 0 projeto gestor, follow up, onco care e call center.

Conforma-se assim uma potente rede de petição e compromissos, onde as "micro-unidades de produção" do cuidado vão se articulando mutuamente, em movimentos interdependentes, sendo a equipe de internação domiciliar, associada ao cuidador, nuclear a todo o esforço que é realizado em torno do funcionamento do programa. Equipe e cuidador aparecem como os gestores do cuidado, gerenciando a assistência ao beneficiário e à família. O corre no ambiente de trabalho certa pactuação em torno da assistência queé ofertada, havendo uma colaboração mútua entre os serviços e equipes, que é coordenada pela gestora da prestadora de serviços de home care. Tudo isso ocorre em sintonia com os objetivos pactuados entre a prestadora e a operadora, que mantém vínculos estreitos com o programa;

b) Multiprofissionalidade: contrariando um pouco o que tem sido a característica dos processos de trabalho na saúde suplementar, sendo estes fortemente centrados no saber ena pessoa do médico, no Programa deAtenção D omiciliar, seja a internação ou os outros cuidados domiciliários, há uma importante característica multiprofissional. A eficácia do programa demanda a operação de diversos saberes que juntos compõem o seu arsenal técnico-assistencial. Há envolvimento direto no trabalho de profissionais médicos, enfermeiros, técnicos de enfermagem, fisioterapeutas, nutricionistas, assi stentes sociais, psicólogos e outros que trabalham no apoio à equipe. Esses profissionais formam entre si uma micro-rede, igualmente dependentes de relações entre si para operar o programa, isto é, a rede é imanente ao processo de trabalho e dele não se desvincula, constituindo-se inclusive informalmente e se comunicando por fluxos de conexão que dão seqüência às linhas de cuidado, operando por dentro dos processos de trabalho. As intencionalidades dos trabalhadores quando operam seu processo de trabalho, demarcadas por suas atitudes na relação com os beneficiários, dá um caráter singular ao modo de cuidar, ou seja, o perfil assistencial que se tem depende do profissional, mais do que qualquer normativa que regula o Programa.

$\mathrm{Na}$ atenção domiciliar, o domicílio, sob o 
ponto de vista do trabalhador, é um lugar que publiciza seu processo de trabalho, o torna mais "exposto" do que o espaço hospitalar, onde o trabalho se dá de forma mais privada, "protegido" pela rígida estrutura organizacional, onde o processo de trabalho é mais controlado pelo saber técnico-científico. As variáveis que compõem o complexo cenário da residência, como, por exemplo, o ambientesociocultural; a condição econômica; as intersubjetividades presentes nas relações de família; o significado da doença no meio familiar são muito ativas e interferem fortemente no cotidiano das práticas de cuidado. Portanto, diferentemente de um hospital, no domicílio tudo isto está em aberto, inclusive o saber técnico-científico é interrogado frente ao saber-cuidador da família, que também tenta se impor no controle do espaço e do projeto terapêutico. Isso explica em parte a forte demanda dos diversos saberes da saúde para operar o Programa, incluindo os do campo da saúde coletiva.

No espaço domiciliar, o trabalho vivo em ato encontra nos fluxos formados com outros trabalhadores, os membros da família e as inumeráveis possibilidades, inclusiveno plano simbólico, um amplo espaço de realização do seu alto grau de liberdade. Assim, a inovadora forma de operação do trabal ho da equipe em domicílio vai possibilitando aos profissionais o uso das suas tecnologias leves e, neste ambiente, podem usar com maior potência a sua capacidade inventiva para resolver problemas desaúdeeinclusiveinteragir melhor com o saber-cuidador da família. Essa é a dimensão não capturada pela normativa institucional, que está no espaço de governo do trabalhador, na sua relação com o beneficiário ea família, e é nesse lugar que se dão as inovações que potencializam o caráter de "substituvididade" das tecnologias de cuidado edas práticas profissionais, que vão ganhando espaço.

0 cuidador é questionado sobretudo "pelo setor de enfermagem" ${ }^{23}$. No entanto, sua necessidade se impõe no Programa de Atenção Domiciliar. A contradição se instala na medida em que as profissões configuram um território ético-legal de exercício profissional e poder sobre o beneficiário. No entanto, na atenção domiciliar, estes limites vão ficando mais tênues, a partir dos "encontros" dos profissionais com os beneficiários e cuidadores, e a ética do cuidado vai se impondo e perpassa os limites interpostos pela ética legal-profissional.

N otadamente que a operadora tem interesse em transferir certos procedimentos para o campo deresponsabilidades do cuidador. Se para eles isto é uma questão que induz à redução de menor trabalho e custos, para o cuidador é al go que surge mais naturalmente a partir de um aprendizado que ele vai tendo no processo, e que se associa ao seu "saber-cuidador" que já lhe era próprio. Percebe-se, nesse meio, uma tensão imanente ao trabal ho e às relações que se constituem nesse cenário, pois os processos de captura do modelo médico-hegemônico, mesmo nos cuidados domiciliários, continuam ativos. 0 modo de produção do cuidado é a resultante das tensões entre a captura e a liberdade, no interior do processo de trabalho, sendo que os dois estarão presentes no curso das relações cuidadoras. A configuração do PAD vai depender decertas condições que se colocam no espaço da micropolítica do trabalho da equipe, definidas em grande medida pelo perfil tecnológico do seu trabalho, e os fatores de subjetivação presentes nas múltiplas relações que operam no espaço de produção. Assim, o perfil assistencial é dado por momentos singulares, que se produzem de forma dinâmica, e não por um continuum que engessa a realidade;

c) Projetos terapêuticos integrais: os planos terapêuticos são elaborados pela equipe de trabalhadores e conduzidos de forma partilhada, articulando os diversos saberes efazeres dos profissionais. É importante registrar que a equipe tem uma grande autonomia na condução do seu processo detrabalho. Isso se verifica no alto grau de flexibilidade na admissão de beneficiários, na possibilidade de pactuação em torno dos projetos terapêuticos e nos critérios de alta que são definidos pela equipe.

A elaboração do projeto terapêutico envolve toda equipe, considera o campo complexo de necessidades do beneficiário ea resposta multifacetada a estas necessidades. A integralidade se verifica na complexa redequese articula em torno da atenção domiciliar eéquaseimperativo para prevenir reinternações do mesmo beneficiário.

o espaço do domicílio é genuinamente o lugar do encontro. 0 encontro aqui é uma categoria que dá significado às múltiplas relações estabelecidas no ambiente de trabalho, reconhecendo que as mesmas produzem "afetamentos" e vão operar subjetivações entre seus protagonistas. No caso estudado, os encontros vêm afetar trabalhadores, cuidador, familiares, com repercussões no processo terapêutico. Deleuze, citando Espinosa, fala do afetamento provocado através dos encontros dos sujeitos entre si e, segundo os autores, os afetos podem provocar afecções al egres ou tristes, produzindo certas potências: 
"a sua potência de agir ou força de existir aumenta ou diminui, visto que a potência do outro modo se lhe junta, ou, ao contrário, se Ihe subtrai, imobilizando-a e fixando- a"20.

Entendemos assim que as afecções alegres provocam "potência de vida" nas relações de cuidado entreequipeecuidador/familiares, enquanto as afecções tristes provocam "potência de morte" nestas relações, o que significa, no plano subjetivo, redução da capacidade de cuidar, de condução de um projeto terapêutico cuidador.

Explicando o tema, partimos do pressuposto que o encontro entre o saber técnico-científico da equipe e o saber-cuidador da família gera conflito. Esta tensão demanda capacidade dialógica, ação acolhedora e aguçada capacidade de pactuação da equipe. Uma postura como essa é capaz de criar, no ambientedomiciliar, potência de produção de vida (aumento da força vital), nos fluxos relacionais circulantes entreequipe, ben eficiário, cuidador e família. Na mesma medida, se há interdição da fala da família e imposição de um projeto centrado apenas no saber técnico da equipe, os fluxos relacionais se produzem enquanto potência de produção de morte (redução da força vital) nos fluxos circulantes nas relações. Queremos com isso afirmar que o modo singular como a equipe trabal ha no seu cotidiano vai atuar no sentido de produzir eficácia, maiores coeficientes de cuidado na condução do projeto terapêutico, o que inclui necessariamente o protagonismo do cuidador e dos familiares;

d) Trabalho "implicado" e o vínculo: a implicação dos trabalhadores com o Programa de Atenção D omiciliar fica evidenteno modo como conduzem seu trabalho, tratando-o como algo que é significado como "projeto existencial", isto é, vai além deuma atividade produtiva. Háuma identificação muito forte com o Programa e isto se manifesta pelas atitudes assumidas pelos trabalhadores no seu processo de trabalho, ou seja, eles significam seu mundo e interagem com ele com base nas representações simbólicas que formaram do que é o cuidado. É como se o mundo da atenção domiciliar não fosse algo apenas como um objeto de trabal ho sobre o qual o profissional intervém, mas ele é incorporado pelo trabalhador, toma conta da sua alma. Assim, o profissional ao operar o seu trabalho vivo em ato 0 faz com base na imagem formada do PAD, que éa expressão da sua subjetividade, diante do trabal ho que exerce no seu cotidiano. Os processos relacionais entre beneficiários e trabalhadores podem ser conduzidos no sentido de produzirem potência de vida, desde que pactuados e 0 saber-científico encontreharmonia com o sabercuidador da família.

Em relação à resistência que a família oferece para a alta, entendemos que essa questão vem atravessada, por um lado, pela cômoda posição de ter uma equipe cuidando do seu familiar no domicílio. I sso é visto pelos familiares como um apoio fundamental para enfrentar esta difícil situação. E, por outro lado, percebemos muito fortemente a questão do direito atravessando o problema, visto que o recurso mais usado pela família para impedir a alta tem sido a ação judicial. 0 ben eficiário quecontratualiza um plano assistencial com a operadora se vê no direito de ter 0 serviço deatenção domiciliar, mesmo que estenão esteja inscrito no contrato. Entendemos que a situação produziu um paradoxo importante, pois ao mesmo tempo em que o PAD não figura no "rol de procedimentos" da operadora, é largamente ofertado; el e não tem existência legal, pois não é contratualizado, mas é reconhecido pelo sistemajurídico, na medida em queestesentencia quanto ao direito da permanência do beneficiário no Programa. Enfim, esse paradoxo aparecenesse estudo, como um "analisador", isto é, revelando o lugar em que o PAD se encontra hoje no espectro geral da regulação. Ele não é regulado pela ANS, apenas pela ANVISA, como já foi aqui mencionado. Entendemos que não deveria haver mesmo uma regulamentação geral sobre o Programa, na medida em que, dado o caráter dinâmico do processo de trabalho, é salutar maiores níveis de liberdade para a atividade criativa que 0 trabalho vivo proporciona. No entanto, seriaconveniente regular sobre al guns aspectos mais críticos do Programa, como a transferência de alguns custos para a família e a alta.

\section{Considerações finais}

Concluímos que o Programa de Atenção Domiciliar da operadora estudada se produz mediante um processo de reestruturação produtiva, isto é, há importantes mudanças no modo de produção do cuidado, mas ainda nos marcos do modelo médico hegemônico enas regras próprias de mercado. Isto pode ser mais bem entendido à luz dos estudos que discutem a formação das instituições médicas no Brasil.

"[...] no Brasil, mais que nas formações sociais avançados do capitalismo, o Estado foi historicamente 0 organizador e é, atualmente, o gerentedas Instituições M édicas, privadas ou não" 21 . A autora revela o quanto as instituições médicas 
historicamente se constituíram por dentro do Estado em certa transversalidade sobre o mesmo, e este age no sentido de incorporá-las à formação social, econômica e cultural da sociedade brasileira, operando no sentido da medicalização da sociedade. Isto está tão arraigado na estrutura social brasileira, que os movimentos de mudança, mesmo os que inauguram novas práticas de cuidado, não tiveram ainda potência para produzir uma ruptura com o modelo médico.

O Programa de Atenção Domiciliar no seu funcionamento cotidiano, e a partir das interações que cria no espaço da micropolítica do pro- cesso de trabal ho, entre profissionais, beneficiários, familiares e toda a rede que se forma em torno desse microcosmo, édispositivo desse processo de reestruturação produtiva. I sso se dá em diferentes graus, às vezes incipiente, sutil e muitas vezes sofrendo atravessamentos de lógicas normativas que demarcam o campo institucional, mas eleestá presente epodeser verificado na singularidade das práticas assistenciais, nos fluxos de conexão dos processos de trabalho, nas redes que se formam em todos os sentidos, buscando sustentar um processo diferente de produção do cuidado.

\section{Colaboradores}

TB Franco, EE M erhy participaram igualmente de todas as etapas da elaboração do artigo. 


\section{Referências}

1. Malta DC, Cecílio LCO, M erhy EE, Franco TB, Jorge AO, Costa MA. Perspectivas da regulação na saúde suplementar diante dos modelos assistenciais. Cien Saude Colet 2004; 9(2):433-444.

2. Agência Nacional de Saúde Suplementar. Duas faces da mesma moeda: microregulação e modelos assistenciais na saúde suplementar. Rio de Janeiro: ANS; 2005.

3. Agência Nacional de Saúde Suplementar. Programa de Qualificação da Saúde Suplementar. Rio de Janeiro: ANS; 2005

4. Lacerda MR, Giacomozzi CM, Oliniski SR, Truppel TC. As categorias da assistência domiciliar e a prática dos profissionais de saúde - pesquisa exploratório-descritiva. [acessado 2007 Out]; [cerca de 14 p.]. Disponível em: http://www.uff.br/objnursing/index.php/nursing/article/view/557/127

5. Brasil. Agência Nacional de Vigilância à Saúde. Resolução da Diretoria Colegiada (RDC) no 11 de 26 de janeiro de 2006. Dispõe sobre o Regulamento Técnico de Funcionamento de Serviços que prestam Atenção Domiciliar. Diário Oficial da União 2006; 30 jan.

6. Lacerda MR, Giacomozzi CM, Oliniski SR, Truppel TC. Atenção domiciliar: modalidades que fundamental sua prática. Saúde e Sociedade [periódico na Internet]. 2006. [acessado 2007 Out]: [8 p.]. Disponível em: http://www.apsp.org.br/saudesociedade

7. Mendes W. Home Care: uma modalidade de assistência à saúde. Rio de Janeiro: UNATI-UERJ; 2001.

8. Pires D. Reestruturação produtiva e trabalho em saúde no Brasil. São Paulo: Annablume/CNTSS; 1998.

9. M erhy EE. Saúde: cartografia do trabalho vivo. São Paulo: Hucitec; 2002. p. 19-40.

10. M erhy $E E$, Franco $T B$. Reestruturação produtiva em saúde. In: Dicionário da Educação Profissional em Saúde. Rio de Janeiro: Escola Politécnica Joaquim Venâncio/Fiocruz; 2006. p. 225-230.

11. Franco TB. Processos de trabalho e transição tecnológica na saúde: um olhar a partir do sistema cartão nacional de saúde [tese]. Campinas (SP): Faculdade de Ciências M édicas, Universidade Estadual de Campinas; 2003.
12. Cecílio LCO, M erhy EE. A integralidade do cuidado como eixo da gestão hospitalar. In: Pinheiro R, $M$ attos RA, organizadores. Construção da integralidade: cotidiano, saberes e práticas em saúde. Rio de Janeiro: IM S-UERJ/ABRASC O; 2003. p. 197-210.

13. Deleuze G, Guattari F. 0 anti-édipo: capitalismo e esquizofrenia. Lisboa: Assírio e Alvim; 1972.

14. Franco TB. As redes na micropolítica do processo de trabalho em saúde. In: Pinheiro R, M attos RA, organizadores. Gestão em Redes: práticas de avaliação, formação e participação na saúde. Rio de Janeiro: CEPESC-IM S-UERJ/ABRASC 0; 2006. p. 459-474.

15. Deleuze G, Guattari F. Mil platôs: capitalismo e esquizofrenia. vol. 1. Rio de Janeiro: Editora 34; 1995.

16. Baremblitt G. Introdução à esquizoanálise. Belo H orizonte: Biblioteca do Instituto Félix Guattari; 1998.

17. M erhy EE, Feuerwerker LCM. Atenção domiciliar: medicalização e substitutividade. 2007. [acessado 2007 Mai 22]; [21 p.]. Disponível em: http://www. hucff.ufrj.br/micropolitica/pesquisas/atencaodomiciliar/textos.php

18. Guattari F. Caosmose. São Paulo: Editora 34; 1998.

19. Altoé S. Lourau: analista institucional em tempo integral. São Paulo: Hucitec; 2004. p. 256-258.

20. Deleuze G. Espinosa: filosofia prática. São Paulo: Escuta; 2002. p. 56-57.

21. Luz MT. As instituições médicas no Brasil: instituição e estratégia de hegemonia. 2ª ed. Rio de Janeiro: Graal; 198.

Artigo apresentado em 10/07/2007

Aprovado em 01/10/2007

Versão final apresentada em 26/11/2007 